\title{
Value of copeptin and the S-100b protein assay in ruling out the diagnosis of stroke- induced dizziness pattern in emergency departments
}

\author{
N. Deboevere ${ }^{1^{*}}$ (D) N. Marjanovic ${ }^{1}$, M. Sierecki ${ }^{1}$, M. Marchetti ${ }^{1}$, M. Dubocage $^{1}$, E. Magimel ${ }^{1}$, O. Mimoz $^{1,2}$ and \\ J. Guenezan ${ }^{1}$
}

\begin{abstract}
Background: Dizziness is a frequent reason for visiting emergency departments (EDs). Differentiating stroke from other causes is challenging for physicians. The role of biomarkers has been poorly assessed. We evaluated whether copeptin and S100b protein (PS100b) assessment, alone or in combination, could rule out stroke in patients visiting EDs for dizziness.

Methods: We included patients 18 years of age or older, visiting the adult ED of a French university hospital for a new episode of dizziness evolving for less than $72 \mathrm{~h}$. All patients underwent standardized physical examination (HINT [Head Impulse test, Nystagmus, test of skew deviation] maneuvers), copeptin and S-100b protein (PS100) measurement and injected brain imaging. Stroke diagnosis involved diffusion-weighted magnetic resonance imaging or, if not available, neurological examination and contrast brain CT scan compatible with the diagnosis.

Results: Of the 135 patients participating in the study, 13 (10\%) had stroke. The sensitivity, specificity and positive and negative predictive values of copeptin/PS100 combination were 100\% (95\%Cl, 77-100\%), 48\% (40-57\%), $14 \%$ $(11-27 \%)$ and 100\% (94-100\%), respectively. Values for copeptin alone were $77 \%$ (Cl95\% 0.50-0.91), 50\% (Cl95\% 0.49-0.58), 14\% (Cl95\% 0.08-0.24), 93\% (Cl95\% 0.87-0.98), and for PS100 alone were 54\% (Cl95\% 0.29-0.77), 97\% (Cl95\% 0.92-0.99), 64\% (Cl95\% 0.35-0.84), 95\% (Cl95\% 0.90-0.98).
\end{abstract}

Conclusions: Absence of copeptin and PS100 elevation seems to ruling out the diagnosis of stroke in patients visiting the ED for a new episode of dizziness. These results need to be confirmed in a large-scale study.

Keywords: Dizziness, stroke, copeptin, PS100b, Biomarker

\section{Introduction}

Dizziness is a common reason for visiting emergency departments (EDs) worldwide $[1,2]$. One of the main difficulties for the emergency physician is to distinguish stroke, which may require urgent neurovascular management, from peripheral etiologies of dizziness [1-5], whose treatment is mainly symptomatic. This difficulty is due to the subjective description of the dizziness by the patient and a lack of homogenized clinical examination by

\footnotetext{
* Correspondence: nicolas.deboevere@chu-poitiers.fr

${ }^{1}$ Service d'Acceuil des Urgences, SAMU 86, Centre Hospitalier Universitaire de Poitiers, 2 rue de la Milétrie, 86021 Poitiers, France

Full list of author information is available at the end of the article
}

physicians. The three HINTS (Head Impulse Test, Nystagmus and Test of Skew Deviation) maneuvers have been proposed to clinically distinguish stroke from other etiologies, but the literature supporting these recommendations is limited [1, 6-13].

In this context, biomarkers could be useful. Copeptin is an endogenous stress marker, secreted by the pituitary gland, having good negative predictive value, particularly in the acute phase of myocardial infarction [14]. S-100b protein (PS100) is a marker of cerebral injury of vascular or traumatic origin [15-17]. Mainly secreted by astrocytes of the central nervous system, PS100 has good negative predictive value to rule out brain injury in mild

(c) The Author(s). 2019 Open Access This article is distributed under the terms of the Creative Commons Attribution 4.0 International License (http://creativecommons.org/licenses/by/4.0/), which permits unrestricted use, distribution, and reproduction in any medium, provided you give appropriate credit to the original author(s) and the source, provide a link to the Creative Commons license, and indicate if changes were made. The Creative Commons Public Domain Dedication waiver (http://creativecommons.org/publicdomain/zero/1.0/) applies to the data made available in this article, unless otherwise stated. 
head trauma [18]. Both biomarkers have been independently linked to severity of stroke [14, 19-24], and their concentrations increase in proportion to the National Institute of Health Stroke Score (NIHSS) value. Because of their different blood appearance kinetics [14-18, 25], early for copeptin and delayed for PS100, their negativity in the acute phase of dizziness has the potential to rule out stroke as its etiology.

We evaluated whether assessment of copeptin and PS100 protein, alone or in combination, in patients visiting an ED for newly developed dizziness could ruling out stroke as its cause.

\section{Methods}

\section{Design of the study}

We conducted a prospective, observational, monocenter study from May 1, 2016 to January 31, 2018 in the adult ED of the University Hospital of Poitiers after submitting the protocol to our local ethics committee (reference 2016-27).

\section{Patients}

We included patients 18 years of age or older, visiting the ED for a new episode of dizziness evolving less than $72 \mathrm{~h}$ and having given written consent to participate in the study.

Non-inclusion criteria were head trauma during the last $72 \mathrm{~h}$, capillary blood glucose level lower than $0.60 \mathrm{~g} / \mathrm{L}$ on admission, toxic substance ingestion within $72 \mathrm{~h}$ of admission, chest pain or pathological electrocardiogram (heart rhythm disorders discovered in the ED), high-grade cardiac conduction disorders, Brugada and Wolff Parkinson White, unknown bradycardia with heart rate $<40 / \mathrm{min}$, acute coronary syndrome).

Patients without brain imaging (diffusion-weighted magnetic resonance imaging (MRI) or contrast CT scan compatible with the diagnosis) were excluded.

\section{Procedures}

We developed a protocol on the management of dizziness in an ED based on published scientific knowledge. Reminders on its application were regularly sent to residents and physicians working in the ED. This protocol included:

- Standardized and validated physical examination of dizziness (HINTS maneuvers) $[6,8,13]$,

- Search for cerebellar ataxia,

- Search for disharmonious vestibular syndrome,

- Immediate call to a specialist (Neurologist or ENT specialist) when requested by attending emergency physician,

- Blood determination of PS100 and copeptin,
- Brain imaging: MRI alone, CT alone or both. Depending on clinical presentation, the imaging tests were performed during ED stay, during hospitalization or externally. Presence or absence of stroke was established on diffusion-weighted brain MRI [26]. In case of normal contrast CT alone, a specialized opinion should exclude the need for diffusion-weighted MRI according to clinical presentation.

\section{Data collection}

Age, sex and time between dizziness onset and ED visit were collected using Resurgences ${ }^{\bullet}$ software (Intuitive, Berger-Levrault, Boulogne - Billancourt, France).

PS100 concentrations were measured on serum samples by electro-chemiluminescence assay (Roche, Mannheim, Germany). Copeptin concentrations were measured on serum samples by the Kryptor method (Thermo Scientific, Hennigsdorf, Germany).

The positivity threshold for copeptin was set, in accordance with the laboratory standard, at strictly above $10 \mathrm{pmol} / \mathrm{L}$ and that of PS100 was set at strictly above $0.105 \mu \mathrm{mol} / \mathrm{L}$.

\section{Statistical analyses}

All data were anonymized and analyzed with Excel ${ }^{\circ}$ software (Microsoft corporation, Redmond, WA, USA). Quantitative variables were described by their median and interquartile and compared using Mann Whitney U test. Qualitative variables were described by their gross number and percentage and compared by a Chi-2 test. A value of $p<0.05$ was considered significant. Sensitivity, specificity, and positive and negative predictive values predicting stroke as the cause of dizziness were calculated for each biomarker alone or in combination.

As this is an exploratory study, we included as many consecutive patients as possible during the inclusion period.

\section{Results}

One hundred and fifty-one patients were included, of whom 16 were secondarily excluded (lost to follow-up $n=1$, missing biomarkers $n=9$, missing MRI $n=6$ ) (Fig. 1). A majority of the remaining 135 patients were women $(n=79,59 \%)$ with an average age of 62 years. Specialized advice on the origin of dizziness was sought from ENT and/or neurologist in 102 (76\%) of cases. Patients received brain diffusion-weighted MRI alone in 74 cases, contrast brain $\mathrm{CT}$ alone in 11 cases and a combination of MRI and CT in 50 cases.

In 122 patients (90\%), vertigo was not related to stroke. Exclusion of this diagnosis was made on normal diffusion-weighted MRI alone or in combination with normal contrast CT in $95 \%$ of cases. The characteristics 


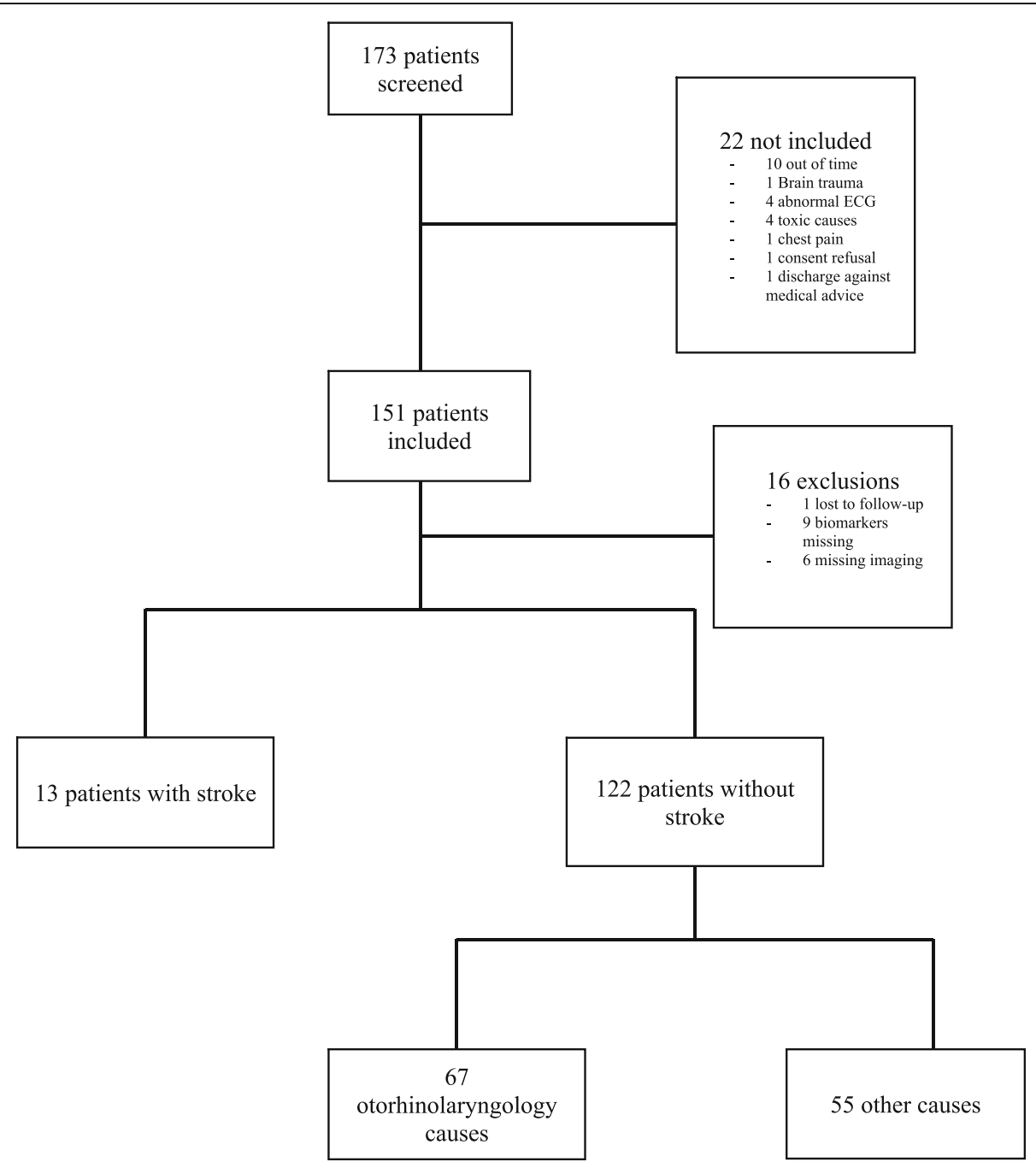

Fig. 1 Study flowchart

of patients with and without stroke are summarized in Table 1. Those with stroke causing dizziness were older. Conversely, there was no difference in gender and time between dizziness onset and clinical examination between the 2 groups.

PS100 and copeptin concentrations above normal values were more frequent in patients having stroke (Table 1) than in those without stroke.

Table 2 shows the performance of copeptin and PS100, alone or in combination, to diagnose or rule out stroke as the cause of dizziness.

\section{Discussion}

In this study, absence of both copeptin and PS100 elevation effectively excluded stroke as the main cause of dizziness in patients visiting EDs for a new episode.

Dizziness is one of the most frequent symptoms occasioning ED visits. One goal for emergency physicians is to eliminate a neurovascular etiology that may require specific management as soon as possible. Typical clinic presentations are quickly referred to a neurologist, but atypical forms pose difficult diagnostic orientations, and may be responsible for treatment delay and worsened outcome. Biomarkers seem to provide diagnostic assistance in situations of uncertainty or difficulty in accessing specific imaging. However, delays in obtaining biomarker results do not currently justify their routine use in patients with highly probable diagnosis of stroke. Brain imaging is preferable, particularly in settings compatible with thrombolysis use. Our results are consistent with those previously reported by Purrucker and colleagues performed in similar patients [27]; in their study, PS100 concentrations were significantly higher in patients with stroke compared to those without $(0.069$ $\mathrm{ng} / \mathrm{ml}$ versus $0.047 \mathrm{ng} / \mathrm{ml}, p<0.001)$, with $94 \%$ sensitivity and $32 \%$ specificity for stroke diagnosis in cases of PS100 elevation. 
Table 1 Patient characteristics, biomarker values and brain imaging type in patients with or without stroke as the main cause of a new episode of dizziness

\begin{tabular}{|c|c|c|c|}
\hline & $\begin{array}{l}\text { Stroke } \\
(n=13)\end{array}$ & $\begin{array}{l}\text { No stroke } \\
(n=122)\end{array}$ & $P$ value \\
\hline Age (yrs) & $70[62-78]$ & $60[42-71]$ & 0.023 \\
\hline Male sex & $6(46)$ & $51(42)$ & 0.76 \\
\hline Delay between dizziness onset and ED visit ( $h$ ) & $12[8.5-30]$ & $12[6-24]$ & 0.395 \\
\hline \multicolumn{4}{|l|}{ Clinical data } \\
\hline Positive HINT maneuvers & $5(38.5)$ & $29(24)$ & 0.246 \\
\hline Positive nystagmus test & $5(38.5)$ & $28(3)$ & 0.216 \\
\hline Positive HIT test & $1(7)$ & $10(8)$ & 1 \\
\hline Positive skew test & $1(7)$ & $1(1)$ & 0.184 \\
\hline \multicolumn{4}{|l|}{ Biomarker data } \\
\hline Copeptin value ( $\mu \mathrm{mol} / \mathrm{L})$ & $70[13.5-141]$ & $10.5[4-31]$ & 0.065 \\
\hline Copeptin >normal value & $10(76)$ & $61(50)$ & 0.002 \\
\hline S100 protein value (pmol/L) & $0.11[0.04-0.65]$ & $0.05[0.04-0.06]$ & $<0.0001$ \\
\hline S100 protein $>$ normal value & $7(54)$ & $4(3)$ & 0.002 \\
\hline \multicolumn{4}{|l|}{ Brain imaging } \\
\hline Tomodensitometry & $5(38)$ & $6(5)$ & 0.001 \\
\hline Magnetic resonance imaging & $3(23)$ & $71(58)$ & 0.02 \\
\hline Both & $5(38)$ & $45(37)$ & 0.91 \\
\hline
\end{tabular}

Results are expressed as median [Interquartile range] or number (percentage)

The interest in combining the two biomarkers is explained by their different kinetic profiles. Copeptin rises in the first hours following endogenous stress and quickly decreases below normal values [19, 26, 28, 29]. Conversely, PS100 increase is delayed after stroke, until brain necrosis occurs, but lasts longer [25] .

Our study has several limitations. First, our population came from a monocentric cohort and the number of patients included ( $n=135)$ was limited, with only 13 stroke episodes. Second, 11 (8\%) included patients did not receive reference brain imaging (MRI). However, the risk of misdiagnosis is probably low since these 11 patients received contrast brain $\mathrm{CT}$ that was either abnormal $(n=5)$, thereby confirming the diagnosis of stroke, or normal $(n=6)$ but, following expert opinion, ruling out stroke.

To the best of our knowledge, our study is the first to examine the value of copeptin and PS100 used in combination as means of ruling out central origin of dizziness in patients visiting EDs for a new episode. Stroke was mainly identified on reference brain imaging. The use of biomarkers is probably not useful in situations where the diagnostic suspicion of stroke is high, especially in the early hours, when imaging diagnoses and guides therapeutic management. Conversely, they could be recommended in situations of uncertainty, where the emergency physician is often alone, with limited access to reference imaging. More studies with larger cohorts are required to confirm our results, and to better define the place of these biomarkers in the diagnostic strategy.

\section{Conclusions}

Absence of copeptin and PS100 elevation seems to ruling out the diagnosis of stroke in patients visiting the ED for a new episode of dizziness. These results need to be confirmed in a large-scale study.

Table 2 Diagnostic values of copeptin and S100 protein, alone or in combination, to ruling out stroke as the main cause of a new episode of dizziness

\begin{tabular}{lllll}
\hline & Sensitivity & Specificity & Positive predictive value & Negative predictive value \\
\hline Copeptin & $0.77[0.50-0.91]$ & $0.50[0.49-0.58]$ & $0.14[0.08-0.24]$ & $0.93[0.87-0.98]$ \\
S100 protein & $0.54[0.29-0.77]$ & $0.97[0.92-0.99]$ & $0.64[0.35-0.84]$ & $0.95[0.90-0.98]$ \\
Both & $1[0.77-1]$ & $0.48[0.40-0.57]$ & $0.14[0.11-0.27]$ & $1[0.94-1]$ \\
\hline
\end{tabular}

Values in brackets are $95 \%$ confidence interval 


\section{Abbreviations}

CT: Computed tomography; EDs: Emergency departments; HINT: Head Impulse test, Nystagmus, test of skew deviation; MRI: Magnetic resonance imaging; NIHSS: National Institute of Health Stroke Score; PS100b: S100b Protein

\section{Authors' contributions}

ND, MS conceived the study. All authors have reviewed and completed protocol study, manuscript. All authors read and approved final manuscript.

\section{Funding}

Not applicable.

\section{Availability of data and materials}

All data generated or analysed during this study are included in this published article [and its supplementary information files].

\section{Ethics approval and consent to participate}

Protocol was submitted to local ethics committee (reference 2016-27) of University Hospital of Poitiers.

\section{Consent for publication}

Not applicable.

\section{Competing interests}

The authors declare that they have no competing interests.

\section{Author details}

'Service d'Acceuil des Urgences, SAMU 86, Centre Hospitalier Universitaire de Poitiers, 2 rue de la Milétrie, 86021 Poitiers, France. ${ }^{2}$ INSERM U1070, Université de Poitiers, Poitiers, France.

Received: 14 June 2019 Accepted: 23 July 2019

Published online: 06 August 2019

\section{References}

1. Tarnutzer AA, Berkowitz AL, Robinson KA, Hsieh Y-H, Newman-Toker DE. Does my dizzy patient have a stroke? A systematic review of bedside diagnosis in acute vestibular syndrome. Can Med Assoc J. 2011;183(9):E571-92.

2. Saber Tehrani AS, Coughlan D, Hsieh YH, Mantokoudis G, Korley FK, Kerber KA, et al. Rising annual costs of dizziness presentations to U.S. Emergency Departments. Schneider S, editor. Acad Emerg Med. 2013;20(7):689-96.

3. Rydzak M. Prise en charge des vertiges au service d'accueil des urgences du CHU de Nancy : analyse des difficultés rencontrées par les médecins urgentistes et mise en place d'une procédure opérationnelle standardisée [Thèse de Doctorat]. Nancy: Faculté de Médecine de Nancy; 2014.

4. Berthélémy S. Les vertiges. Dans : Encyclo Med Chir, Actualités pharmaceutiques [Article 549 ; 34 :38]; 2011.

5. Manzoor AM, Albaradie RS. Inflammation and anti-inflammatory Stategies in stroke. W J Pharm Res. 2014:3(4):361-95.

6. Kamei T, Kimura K, Kaneko H, Noro H. Revaluation of the head shaking test as a method of nystagmus provocation. 1. Its nystagmus-eliciting effect. Nippon Jibiinkoka Gakkai Kaiho. 1964;67:1530-4.

7. Volgger V, Gürkov R. Acute vestibular syndrome in cerebellar stroke : a case report and review of the literature. HNO. 2017;65(Suppl 2):149-52.

8. Batuecas-Caletrío A, Yáñez-González R, Sánchez-Blanco C, González-Sánchez E, Benito J, Gómez JC, et al. Peripheral vertigo versus central vertigo. Application of the HINTS protocol. Rev Neurol. 2014;59(8):349-53.

9. Kattah JC, Talkad AV, Wang DZ, Hsieh Y-H, Newman-Toker DE. HINTS to diagnose stroke in the acute vestibular syndrome: three-step bedside oculomotor examination more sensitive than early MRI diffusion-weighted imaging. Stroke. 2009;40(11):3504-10

10. Venhovens J, Meulstee J, Verhagen WIM. Acute vestibular syndrome: a critical review and diagnostic algorithm concerning the clinical differentiation of peripheral versus central aetiologies in the emergency department. J Neurol. 2016;263(11):2151-7.

11. Cohn B. Can bedside oculomotor (HINTS) testing differentiate central from peripheral causes of Vertigo? Ann Emerg Med. 2014;64(3):265-8.

12. Carmona S, Martínez C, Zalazar G, Moro M, Batuecas-Caletrio A, Luis L, et al. The diagnostic accuracy of truncal Ataxia and HINTS as cardinal signs for acute vestibular syndrome. Front Neurol. 2016;7:125 Cited 2019 Apr 28.
13. Newman-Toker DE, Kerber KA, Hsieh Y-H, Pula JH, Omron R, Saber Tehrani AS, et al. HINTS outperforms ABCD2 to screen for stroke in acute continuous Vertigo and dizziness. Goldstein JN, editor. Acad Emerg Med. 2013:20(10):986-96.

14. Chenevier-Gobeaux C, Billemont M, Eche A, Trabattoni E, Kierzek G, Pourriat $\mathrm{J}-\mathrm{L}$, et al. Nouveaux biomarqueurs de la pathologie cardiovasculaire et infectieuse en médecine d'urgence. Réanimation. 2010;19(7):648-54.

15. Beaudeux JL, Roche S, Puyssabet L, Foglietti MJ. Physiopathologie de la protéine S-100b et apport de son dosage dans les pathologies neurologiques. In: Encyclo Med Chir, immunoanalyse et biologie spécialisée [Article $16 ; 143: 148] ; 2001$

16. Beaudeux JL, Soler C, Foglietti MJ. Physiopathologie de la protéine S-100b : intérêt de son dosage en biologie clinique. In: Encyclo Med Chir, immunoanalyse et biologie spécialisée [Article $17 ; 280$ : 286]; 2002.

17. Gaillard O. La protéine S-100b, profil immunoanalytique en biologie clinique. In: Encyclo Med Chir, immunoanalyse et biologie spécialisée [Article 17; 363: 365]; 2002.

18. Undén L, Calcagnile O, Undén J, Reinstrup P, Bazarian J. Validation of the Scandinavian guidelines for initial management of minimal, mild and moderate traumatic brain injury in adults. BMC Med. 2015;13(1):292.

19. Katan M, Fluri F, Morgenthaler NG, Schuetz $P$, Zweifel C, Bingisser $R$, et al. Copeptin: a novel, independent prognostic marker in patients with ischemic stroke. Ann Neurol. 2009;66(6):799-808.

20. Beaudeux JL, Watremez C, Koskas F, Godet G, Foglietti MJ. La protéine S100b, marqueur de souffrance cérébrale au cours des endartériectomies carotidiennes ? In: Encyclo Med Chir, immunoanalyse et biologie spécialisée [Article $15 ; 205: 206] ; 2000$.

21. Kokocinska D, Wieczorek P, Partyka R, Jarzab J, Jałowiecki P, Sikora J. The diagnostic utility of S-100B protein and TPA in patients with ischemic stroke. Neuro Endocrinol Lett. 2007;28(5):693-8.

22. Nash DL, Bellolio MF, Stead LG. S100 as a marker of acute brain ischemia: a systematic review. Neurocrit Care. 2008;8(2):301-7.

23. Kumar H, Lakhotia M, Pahadiya H, Singh J. To study the correlation of serum S-100 protein level with the severity of stroke and its prognostic implication. J Neurosci Rural Pract. 2015;6(3):326.

24. Herrmann M, Vos P, Wunderlich MT, de Bruijn CH, Lamers KJ. Release of glial tissue-specific proteins after acute stroke: a comparative analysis of serum concentrations of protein S-100B and glial fibrillary acidic protein. Stroke. 2000;31(11):2670-7.

25. Beaudeux JL. Accidents vasculaires cérébraux : de nouveaux marqueurs biologiques en perspective. In: Dans Enc Med Chir, revue francophone des laboratoires [Article 409 ; 75 : 80]; 2009.

26. Desbene C, Gaillard O. Caractéristiques immuno-analytiques de la copeptine. In: Encyclo Med Chir, Immuno-analyse et biologie spécialisée [Article $28 ; 386: 392] ; 2013$.

27. Purrucker JC, Herrmann O, Lutsch JK, Zorn M, Schwaninger M, Bruckner T, et al. Serum protein $S 100 \beta$ is a diagnostic biomarker for distinguishing posterior circulation stroke from Vertigo of nonvascular causes. Eur Neurol. 2014;72(5-6):278-84

28. Oppenheim C, Stanescu R, Dormont D, Crozier S, Marro B, Samson Y, et al. False-negative diffusion-weighted MR findings in acute ischemic stroke. AJNR Am J Neuroradiol. 2000;21(8):1434-40.

29. Szmydynger-Chodobska J, Fox LM, Lynch KM, Zink BJ, Chodobski A. Vasopressin amplifies the production of Proinflammatory mediators in traumatic brain injury. J Neurotrauma. 2010;27(8):1449-61.

\section{Publisher's Note}

Springer Nature remains neutral with regard to jurisdictional claims in published maps and institutional affiliations. 